\title{
Deuterium retention in carbon fibre composites NB31 and N11 irradiated with low-energy $D$ ions
}

\author{
J. Roth ${ }^{1}$, V.Kh. Alimov ${ }^{2}$, A.V. Golubeva ${ }^{1}$, R.P. Doerner ${ }^{3}$, J. Hanna ${ }^{3}$, E. Tsitrone ${ }^{4}$, \\ Ch. Brosset ${ }^{4}$, V. Rohde ${ }^{1}$, A. Herrmann ${ }^{1}$, M. Mayer ${ }^{1}$ \\ ${ }^{1}$ Max-Planck-Institut für Plasmaphysik, EURATOM Association, D-85748 Garching, Germany \\ ${ }^{2}$ Institute of Physical Chemistry and Electrochemistry, Russian Academy of Sciences, \\ Leninsky prospect 31, 119991 Moscow, Russia \\ ${ }^{3}$ University of California - San Diego, La Jolla, CA 92093-0417, USA \\ ${ }^{4}$ Association EURATOM-CEA, CEA/DSM/DRFC Cadarache, 13108 St.Paul lez Durance, France
}

\begin{abstract}
Plasma facing carbon fibre composites (CFC) are used for Tore Supra (CFC N11), ASDEX Upgrade (CFC DMS 701) and foreseen for ITER (CFC NB31). Therefore, deuterium retention in the CFC NB31 and N11 was studied by irradiation with 30 to $200 \mathrm{eV}$ D ions, both from ion beams and plasma devices (PISCES-A, Magnetron plasma device), using methods of the thermal desorption spectrometry and $\mathrm{D}\left({ }^{3} \mathrm{He}, \mathrm{p}\right) \stackrel{4}{\mathrm{He}}$ nuclear reaction in a resonance-like technique.

It is found that at each irradiation temperatures in the range from 50 to $450^{\circ} \mathrm{C}$ the amount of deuterium trapped in the CFCs increases with the ion fluence, $\Gamma$. No saturation is reached as observed in pyrolytic graphite. At room temperature the retention at high fluence increases proportional to $\Gamma^{0.5}$.

Depth profiles show that saturation occurs only within a near surface layer corresponding to the ion range. The increase in total retention is accompanied by an increasing long profile tail extending beyond $14 \mu \mathrm{m}$ with the $\mathrm{D}$ concentration above $10^{-1}$ at. $\%$ at fluences above $10^{24} \mathrm{D} / \mathrm{m}^{2}$.

Analysis of CFC and fine-grain graphite tiles removed from identical strike-point positions in the outer ASDEX Upgrade divertor show an order of magnitude higher retention in the CFC and profiles extending into the bulk with concentrations of $0.1 \mathrm{at} \%$ well beyond the measurable depth of $14 \mu \mathrm{m}$.
\end{abstract}




\section{Introduction}

Because of its favourable thermo-mechanical properties carbon fibre composite (CFC) materials are widely used as plasma-facing components in modern fusion experimental machines like JET, JT-60U, ASDEX Upgrade, Tore Supra $\left[{ }^{1}\right]$, and currently are the candidate material for the vertical targets of the divertor plates of ITER. Hydrogen isotope retention and permeation are important for fuel inventory control in the vacuum vessels of fusion reactors and, for the case of tritium application, in safety evaluation and tritium processing design. Thus, data related to long-term plasma-CFC interactions are of interest and extremely important.

In dense pyrolytic graphite the retention of implanted hydrogen isotopes saturates when the concentration in the implantation range reaches about 30 at $\%\left[^{2}\right]$. In fine grain graphites with a typical density around $1,85 \mathrm{~g} / \mathrm{cm}^{3}$ a slow increase in retention with ion fluence was found $\left[{ }^{3}, 4\right]$.In doped CFC materials, a steeper increase in retention and diffusion far beyond the ion range was observed $\left[{ }^{5}\right]$. A deep penetration of deuterium into carbon fibre material CF222 (up to 2-3 mm) was reported after its exposure to the PISCES-A plasma $\left[{ }^{6}\right]$. Tritium depth profiles in divertor tiles retrieved from TFTR and JET have revealed that a large fraction (up to $61 \%$ ) of the retained tritium had diffused deeply into the bulk (up to 20 $\mathrm{mm}$ ) of the 2D (two-dimensional) CFC tiles from JET in comparison to only few percent found in the 4D CFC tile from TFTR $\left[{ }^{7},{ }^{8}, 9\right]$.

In Tore Supra long pulse discharges deuterium particle balance suggests that a constant fraction of the injected gas (typically 50\%) is retained in the wall for the duration of the shot. No sign of wall saturation after more than 6 min discharge [1] is observed.

In the present work deuterium retention in 3D CFC materials NB31 and N11 was studied by irradiation with 30 to $200 \mathrm{eV} \mathrm{D}$ ions, both from ion beams and plasma devices, using methods of the thermal desorption spectrometry and $\mathrm{D}\left({ }^{3} \mathrm{He}, \mathrm{p}\right)^{4} \mathrm{He}$ nuclear reaction in a resonance-like technique. The depth profiles and total inventory were compared to results obtained from $\mathrm{CFC}$ and fine grain graphite divertor tiles removed from identical strike-point positions in the outer ASDEX Upgrade divertor.

\section{Experimental}

Two types of 3D CFC materials provided by SEP (Bordeaux, France), NB31 (density $\rho=$ $\left.1.9 \mathrm{~g} / \mathrm{cm}^{3}\right)$ and N11 $\left(\rho=1.71-1.78 \mathrm{~g} / \mathrm{cm}^{3}\right)$, were investigated. The open porosity of the 
materials is $8 \%$ and $12 \%$, respectively. The samples were cut from CFC blocks mechanically and no further treatment was performed. Data are shown for the orientation of highest thermal conductivity perpendicular to the surface. The materials used for the divertor tiles in ASDEX Upgrade were 3D CFC DMS701 from Dunlop ( $\rho=1.75-1.90$ $\mathrm{g} / \mathrm{cm}^{3}$, open porosity $\left.\leq 15 \%\right)$ and fine grain graphite R $6710\left(\rho \geq 1.80 \mathrm{~g} / \mathrm{cm}^{3}\right.$, closed porosity) from Ringsdorf, Germany.

The samples were subjected to D ion irradiation and D plasma exposure in four setups. The irradiation of the CFC NB31 samples with $200 \mathrm{eV}$ D ions was performed at IPP Garching in a vacuum chamber connected to a high-current ion source $\left[{ }^{10}\right]$ at normal ion incidence. The ion flux was $(3.6 \pm 1.1) \times 10^{19} / \mathrm{m}^{2} \mathrm{~s}$ for $200 \mathrm{eV} \mathrm{D}^{+}$and different fluences were achieved by changing the irradiation time. By electron bombardment from the rear of the samples the temperature could be varied from 50 to $450^{\circ} \mathrm{C}$.

The CFC-NB31 samples were also exposed to a deuterium plasma at exposure temperatures between 40 and $675^{\circ} \mathrm{C}$ at IPCE Moscow $\left[{ }^{11}\right]$. Considering that $\mathrm{D}_{2}^{+}$ions dominate in the plasma, the mean energy of D ions was estimated to be approximately 200 $\mathrm{eV}$. The ion flux was determined from ion current measurements and was estimated to be $(1.1 \pm 0.2) \times 10^{21} \mathrm{D} / \mathrm{m}^{2} \mathrm{~s}$. The CFC samples were exposed to the D plasma for $30 \mathrm{~min}$, resulting in an ion fluence of about $2 \times 10^{24} \mathrm{D} / \mathrm{m}^{2}$. During plasma exposure the sample temperature was controlled by a chromel-alumel thermocouple attached to the front surface of the sample outside the irradiation area. The variation of the sample temperature was $\pm 15^{\circ} \mathrm{C}$.

The CFC-N11 samples were exposed to low-energy (about 100-150 eV/D) and highflux (about $2 \times 10^{22} \mathrm{D} / \mathrm{m}^{2} \mathrm{~s}$ ) deuterium plasmas in PISCES-A (UCSD) $\left[{ }^{12}\right]$. Temperatures between 180 and $510^{\circ} \mathrm{C}$ were achieved by varying the plasma parameters and consequently the ion flux. Fluences between $5 \times 10^{24}$ and $1 \times 10^{26} \mathrm{D} / \mathrm{m}^{2}$ were reached.

The CFC DMS 701 and fine grain graphite R 6710 were used as neighboring outer divertor tiles during the full campaign 2004/2005 in ASDEX Upgrade. The tiles covered regions: Strong co-deposition in the private flux zone, and implantation and erosion near the separatrix strike point and in the SOL plasma. Temperatures ranged from near room temperature up to $>650^{\circ} \mathrm{C}$ near the separatrix in type I ELM discharges and fluences varied from 1.5 to $7.5 \times 10^{25} \mathrm{D} / \mathrm{m}^{2}$ as measured by embedded Langmuir probes. More details will be published in $\left[{ }^{13}\right]$. 
Deuterium depth profiles were determined by the $\mathrm{D}\left({ }^{3} \mathrm{He}, \mathrm{p}\right){ }^{4} \mathrm{He}$ nuclear reaction in a resonance-like technique at IPP Garching $\left[{ }^{14}\right]$. Note that the profiles were determined 5-30 days after the $\mathrm{D}$ ion irradiation or $\mathrm{D}$ plasma exposure. To determine the $\mathrm{D}$ concentration up to a depth of around $14 \mu \mathrm{m}$, the energy of the analyzing beam of ${ }^{3} \mathrm{He}$ ions was varied from 0.69 to $3.2 \mathrm{MeV}$. The protons from the nuclear reaction were counted using a wide-angle proton detector, and the computer program SIMNRA was used for the deconvolution of the proton yields measured at different ${ }^{3} \mathrm{He}$ ion energies. A deuterium depth distribution was assumed, and the proton yield as a function of incident ${ }^{3} \mathrm{He}$ energy was calculated. The form of the D depth profile was then varied using an iterative technique until the calculated curve matched the measured proton yields [14].

Total D inventories were determined by thermal desorption spectroscopy (TDS). The samples were heated to $1200^{\circ} \mathrm{C}$ at a linear rate of about $3 \mathrm{~K} / \mathrm{s}$ and kept at this temperature for 3 min. $\mathrm{H}_{2}, \mathrm{HD}, \mathrm{D}_{2}$ partial pressures as well as mass signals for $\mathrm{CD}_{4}$ and heavier hydrocarbons were recorded using a quadrupole mass spectrometer. The set up and calibration procedure is published in $\left[{ }^{15}\right]$.

\section{Results and Discussion}

\section{$\underline{\text { Deuterium retention }}$}

At all irradiation temperatures in the range from 50 to $450^{\circ} \mathrm{C}$ the amount of deuterium trapped in the CFC materials increases with the ion fluence, $\Gamma$ (Fig. 1). No saturation was reached as had been previously observed in pyrolytic graphite [2]. At room temperature the retention increase proceeds proportional to $\Gamma^{0.5}$. At a temperature of $200-250^{\circ} \mathrm{C}$ very similar retention values are obtained, while at $450{ }^{\circ} \mathrm{C}$ the retention decreases by about a factor of 3. The retention trend for $30 \mathrm{eV}$ proceeds as for $200 \mathrm{eV}$, the absolute values being a factor of 3 lower. The $30 \mathrm{eV}$ data are not shown in Fig. 1 for clarity.

A very similar behaviour was found for the N11 samples exposed to the PISCES-A plasma. Data for a bias voltage of $150 \mathrm{eV}$ and temperatures between 200 and $400{ }^{\circ} \mathrm{C}$ are shown in Fig. 1. As the targets were heated by the incident plasma beam the temperature was not stable throughout the implantation and varied by $\pm 50^{\circ} \mathrm{C}$. This may be the reason for the relatively large scatter of the data. Even at the highest fluences, of about $2 \times 10^{26}$ $\mathrm{D} / \mathrm{m}^{2}$, no saturation is reached. 


\section{Deuterium depth profiles}

In the CFC NB31 irradiated at $50^{\circ} \mathrm{C}$ with $200 \mathrm{eV} \mathrm{D}$ ions, the $\mathrm{D}$ depth profile is characterized by the near-surface maximum and by a long diffusion tail into the bulk, increasing with ion fluence. The maximum D concentration in the near-surface layers is about 10 at.\%. Taking into consideration the roughness of the CFC surface and finite depth resolution of the NRA technique, the actual D surface concentration may be higher. Depth profiles show that saturation occurs only within a near surface layer equivalent to the ion range. The near-surface maximum widens as the fluence increases. For fluences above $5 \times 10^{24} \mathrm{D} / \mathrm{m}^{2}$, the tail extends beyond $14 \mu \mathrm{m}$ with $\mathrm{D}$ concentrations around $10^{-1}$ at.\% (Fig. 2a). A comparison of the D depth profiles in pyrolytic graphite HPG and carbon fiber composite NB31 irradiated with $200 \mathrm{eV} \mathrm{D}$ ions at $50^{\circ} \mathrm{C}$ to practically the same fluence of $(1.0-1.5) \times 10^{23} \mathrm{D} / \mathrm{m}^{2}$ (Fig. 2a) clearly demonstrates that the structure of the CFC NB31 allows deuterium to penetrate into the bulk even at room temperature while no diffusion tail is observed in HPG $\left[{ }^{16}\right]$.

An increase of the irradiation temperature leads to the decrease of the D concentration both in the near-surface layers and in the bulk of the CFC NB31 (Fig. 2b). It should be noted that lengths of the profile tails for the same fluence only weakly depend on the irradiation temperature. From data shown in Fig. 2 diffusion coefficients as function of temperature can be evaluated from the profile tail, but these results will be object of a coming paper for a detailed description. The total amount of deuterium trapped in the CFC materials, as obtained from the integration of the depth profile, decreases strongly with the irradiation/exposure temperature. While the irradiation/exposure temperature increases from 190 to about $680^{\circ} \mathrm{C}$, the $\mathrm{D}$ content decreases by about one order of a magnitude.

\section{Deuterium retention in CFC and fine-grain graphite tiles exposed in ASDEX Upgrade}

Two tiles of CFC DMS701 were exposed in the ASDEX Upgrade divertor and compared to identical neighbouring tiles made from fine-grain graphite R 6710. Fig. 3 shows the irradiation conditions along the tiles' surface, the permanence time of the separatrix position, the incident ion fluence as measured by embedded Langmuir probes and the region of intense heating (from 380 to $680{ }^{\circ} \mathrm{C}$ ) during discharges with type I ELMs. In the lower part the retained D amount is compared for $\mathrm{CFC}$ and fine grain graphite. 
Much larger retention of D can be found in the CFC compared to the fine-grain graphite with exception of small s values, where intense co-deposition of $\mathrm{D}$ with $\mathrm{C}$ in the private flux region occurred. Over the rest of the tiles, erosion and implantation dominate. It is evident that in regions of intense occasional heating, due to ELMs, large amounts of D are released, but the ratio of retention in CFC to fine grain graphite becomes largest. This can be interpreted by near surface release of deuterium while D in the bulk of CFC is retained.

This interpretation is corroborated by the respective depth profiles in $\mathrm{CFC}$ and fine grain graphite (Fig. 4). The R 6710 graphite shows a narrow surface profile, saturating the ion range with a weak tail into the bulk due to the porosity. On the contrary, in CFC long tails extending well beyond $14 \mu \mathrm{m}$ are found. Especially in the high temperature region at positions around $1125 \mathrm{~mm}$, the surface is depleted from $\mathrm{D}$, but a fraction diffuses deeply into the bulk, and shows concentrations above 0.1 at $\%$ well beyond the analysis depth of this experiment.

\section{Conclusions}

The structure of CFC is composed of the largely different materials making up the fibres and the matrix. Its layered fibre structure and large porosity between the layers allows hydrogen to penetrate more deeply into the material than into fine-grain graphite. In finegrain graphite quasi-saturation of the retention occurs, whereas the retention in CFC increases roughly with fluence as $\Gamma^{0.5}$. Therefore, at the fluences reached in the experimental campaigns of today's tokamaks, the retention in CFC can exceed the retention in fine-grain graphite by an order of magnitude.

The hydrogen isotope retention due to implantation and migration into CFC materials appears relevant in the explanation of the high amount of deuterium retained in Tore Supra during long pulses $\left[{ }^{17}\right]$.

\section{Acknowledgements}

We thank J. Dorner and M. Fußeder (IPP Garching) for technical assistance with the ${ }^{3} \mathrm{He}$ beam analyses, A. Weghorn (IPP Garching) for the D ion irradiation and D. Komarov (IPCE Moscow) for the D plasma exposure. One of us, V. Alimov, gratefully acknowledges financial support from the Max-Planck-Institut für Plasmaphysik and is 
candidly indebted to his colleagues in the Materialforschung Division of IPP for their warm hospitality during his stay in Garching. The portion of the work performed at the Institute of Physical Chemistry and Electrochemistry, Moscow, was supported by the ISTC under Project 2805. 


\section{Figure captions:}

Fig. 1: D retention in CFC materials compared to pyrolytic graphite [4] as a function of incident ion fluence. Irradiations for CFC NB31 were done using ion beams, CFC N11 was irradiated in the PISCES-A facility.

Fig. 2: Depth profiles of D in CFC NB31 and pyrolytic graphite HPG irradiated with 200 $\mathrm{eV} \mathrm{D}$ ions at room temperature and various fluences (a) and in CFC NB31 exposed to D magnetron plasma [11] to a fluence of $2 \times 10^{24} \mathrm{D} / \mathrm{m}^{2}$ at various temperatures (b).

Fig. 3: a) - Exposure conditions of the strike point tiles in the outer divertor of ASDEX Upgrade during the campaign 2004/2005 vs. vertical coordinate of the tiles (see insert). b) The retained amount of $\mathrm{D}$ from the integrated depth profiles for $\mathrm{CFC}$ and fine grain graphite.

Fig. 4: Depth profiles of D in the strike-point tiles of the outer divertor of ASDEX Upgrade for CFC (a) and fine grain graphite (b). The $S$-coordinate is the same as in fig. 3. 


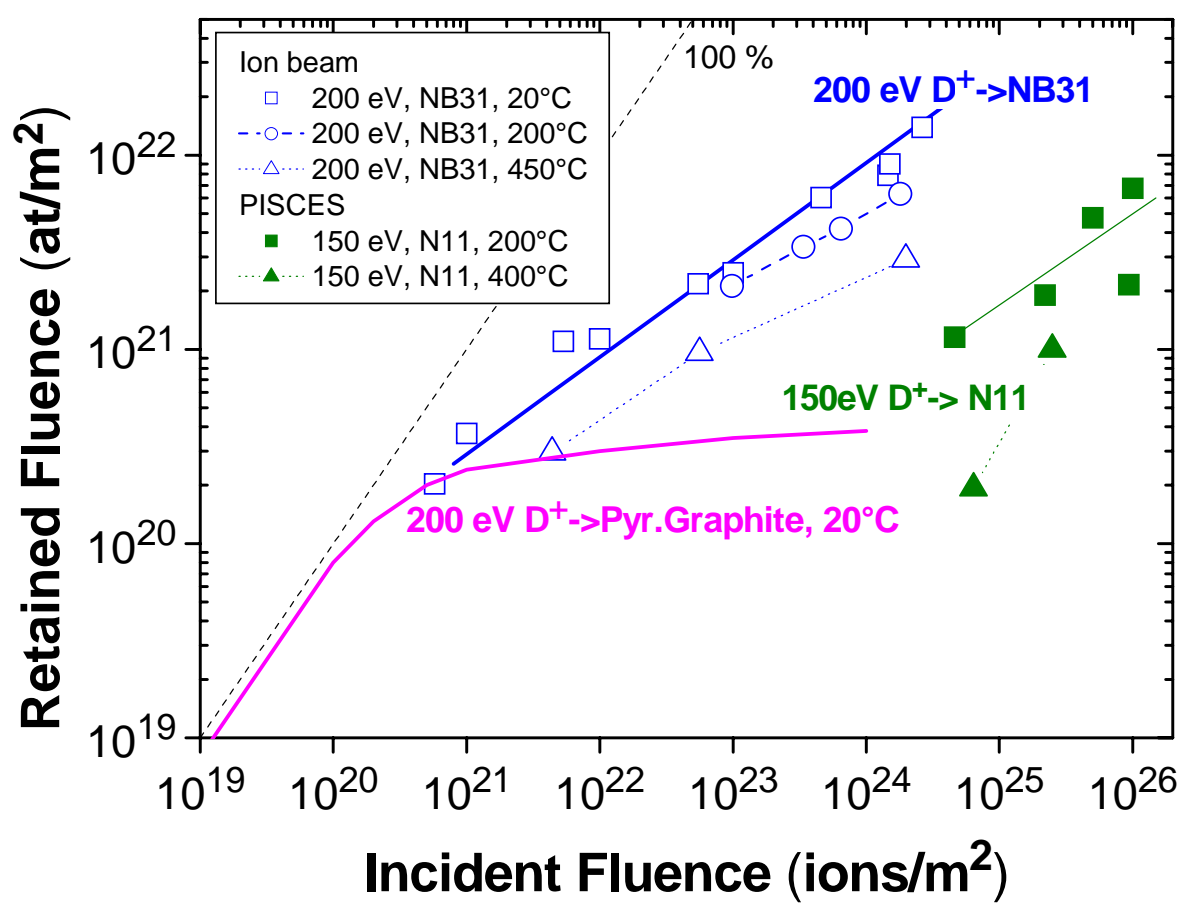

Fig. 1: D retention in CFC materials compared to pyrolytic graphite [4] as function of incident ion fluence. Irradiations for CFC NB31 were done using ion beams, CFC N11 was irradiated in the PISCES-A facility. 

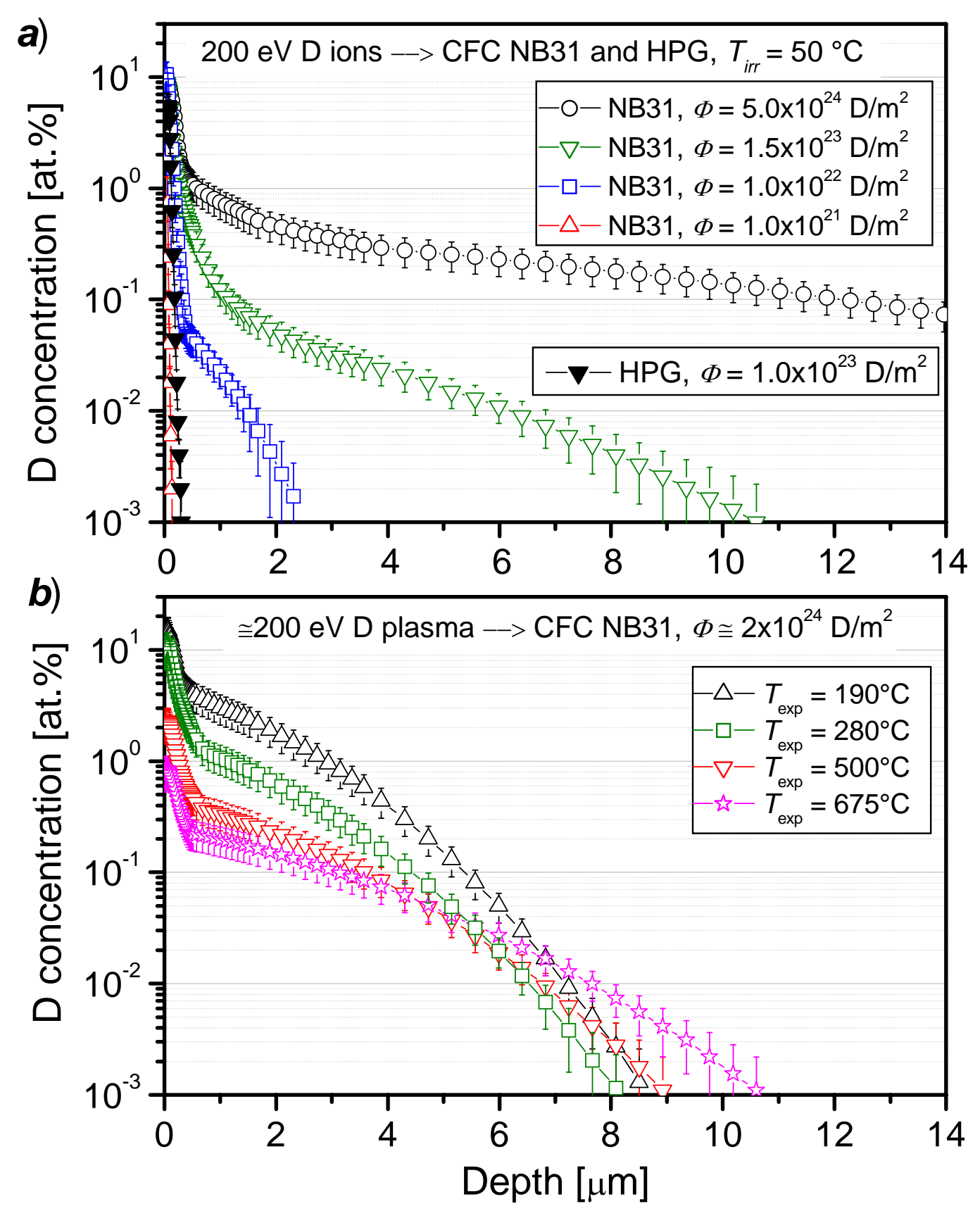

Fig. 2: Depth profiles of D in CFC NB31 and pyrolytic graphite HPG irradiated with 200 $\mathrm{eV} \mathrm{D}$ ions at room temperature and various fluences (a) and in CFC NB31 exposed to D magnetron plasma [11] to a fluence of $2 \times 10^{24} \mathrm{D} / \mathrm{m}^{2}$ at various temperatures (b). 

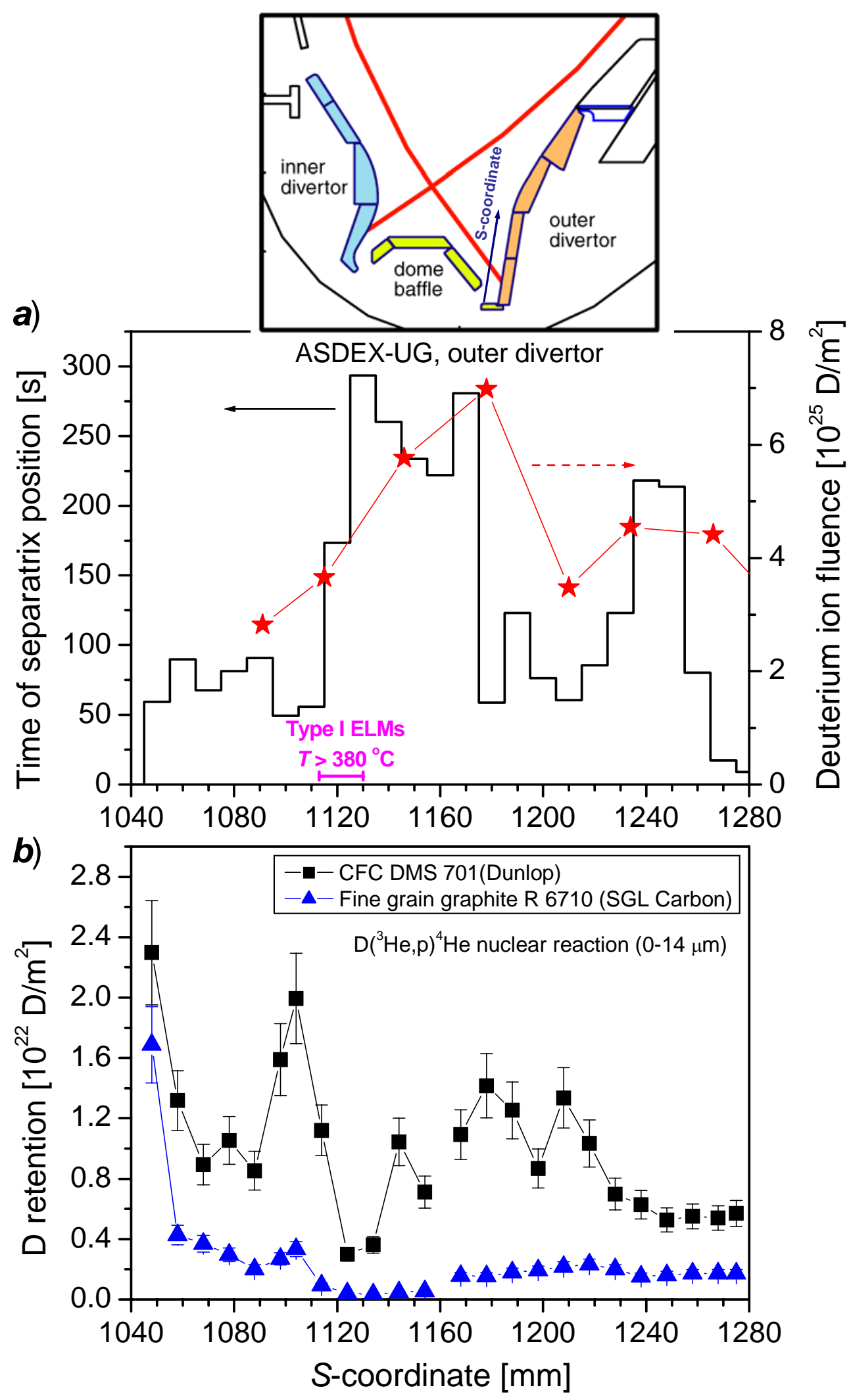

Fig. 3: a) - Exposure conditions of the strike point tiles in the outer divertor of ASDEX Upgrade during the campaign 2004/2005 vs. vertical coordinate of the tiles (see insert). b) The retained amount of $\mathrm{D}$ from the integrated depth profiles for $\mathrm{CFC}$ and fine grain graphite. 

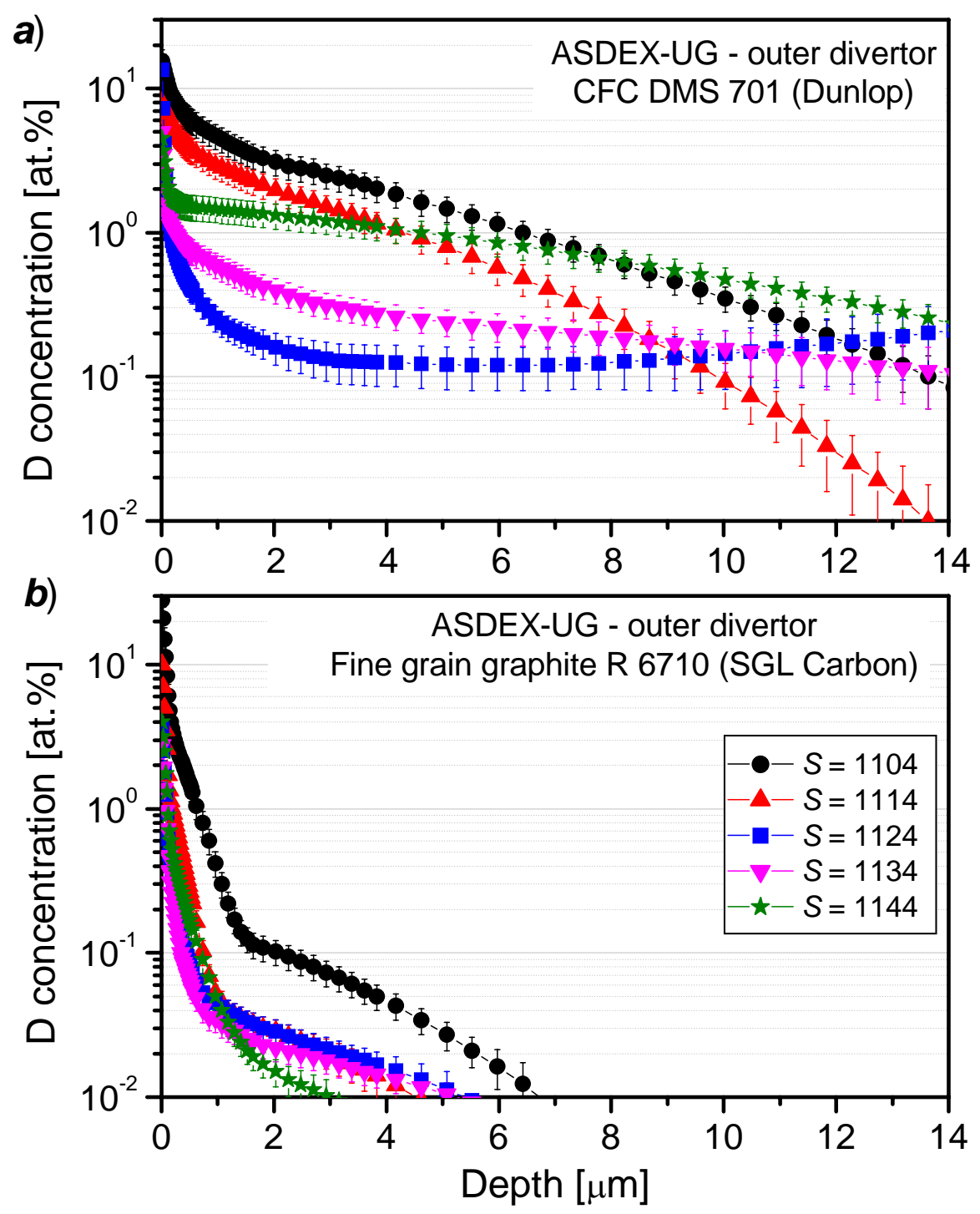

Fig. 4: Depth profiles of D in the strike-point tiles of the outer divertor of ASDEX Upgrade for CFC (a) and fine grain graphite (b). The $S$-coordinate is the same as in fig. 3. 


\section{References}

E. Tsitrone, D. Reiter, T. Loarer, C. Brosset, J. Bucalossi, L. Begrambekov,

C. Grisolia, A. Grosman, J. Gunn, J. Hogan, R. Mitteau, B. Pérourié, P. Ghendrih,

R. Reichle, P. Roubin, J. Nucl. Mater. 337-339 (2005) 539.

$2 \quad$ G. Staudenmaier, J. Roth et al., J. Nucl. Mater. 84 (1979) 149.

3 A.A. Haasz, J. Davis, J Nucl. Mater. 209 (1994) 1140.

$4 \quad$ M. Balden et al., Physica Scripta T102 (2003) 38.

$5 \quad$ M. Mayer et al. J. Nucl. Mater. 252 (1998) 55.

$6 \quad$ B. Emmoth, M. Rubel, E. Franconi, Nucl. Fusion 30 (1990) 1140.

7 R.-D. Penzhorn, N. Bekris, U. Berndt, J.P. Coad, H. Ziegler, W. Nägele, J. Nucl. Mater. 288 (2001) 170. R.-D. Penzhorn, J.P. Coad, N. Bekris, L. Doerr, M. Friedrich, W. Pilz, Fus. Eng. Des. 56\&57 (2001) 105. N. Bekris, C.H. Skinner, U. Berndt, C.A. Gentile, M. Glugla, B. Schweigel, J. Nucl. Mater. 313-316 (2003) 501. (2006) 282.

12 D.M. Goebel, J. Bohdansky, R.W. Conn, Y. Hirooka, B. LaBombard, W.K. Leung, R.E. Nygren, J. Roth, G.R. Tynan, Nucl. Fusion, 28 (1988) 1041.

13 M. Mayer, V. Rohde, to be published

$14 \quad$ V.Kh. Alimov, M. Mayer, J. Roth, Nucl. Instr. and Meth. B 234 (2005) 169.

15 O.V. Ogorodnikova, M. Mayer, J. Roth, J. Nucl. Mater. 313-316 (2003) 469.

16 J. Roth et al., J. Nucl. Mater. 93\&94 (1980) 601.

17 C. Brosset et al., this conference 